\title{
Starlike Branched Polyacrylamides by RAFT Polymerization-Part I: Synthesis and Characterization
}

\author{
Benjamin Klemm, ${ }^{\dagger}$ Francesco Picchioni, $^{\dagger, \ddagger}{ }^{\ddagger}$ Frank van Mastrigt, ${ }^{\dagger, \dagger}$ and Patrizio Raffa $*, \dagger \odot$ \\ ${ }^{\dagger}$ Department of Chemical Engineering, University of Groningen, Nijenborgh 4, 9747 AG Groningen, The Netherlands \\ ${ }^{\ddagger}$ Dutch Polymer Institute (DPI), P.O. Box 902, 5600 AX Eindhoven, The Netherlands
}

\section{Supporting Information}

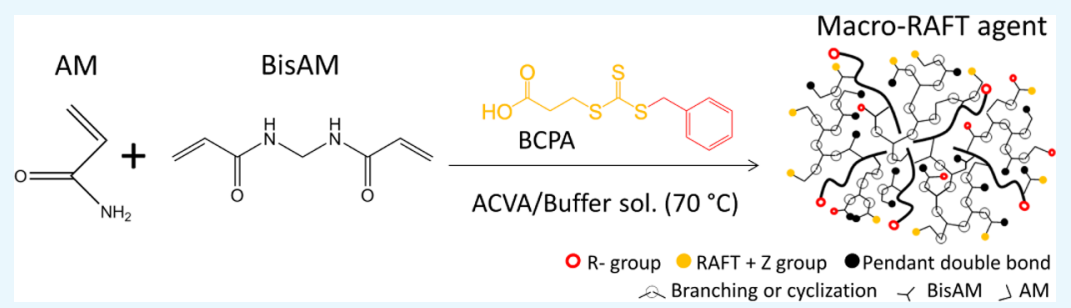

ABSTRACT: Starlike branched polyacrylamides (SB-PAMs) were synthesized using reversible addition-fragmentation chain transfer copolymerization of acrylamide (AM) and $N, N^{\prime}$-methylenebis(acrylamide) (BisAM) in the presence of 3(((benzylthio) carbonothioyl)thio)propanoic acid as a chain transfer agent, followed by chain extension with AM. The amount of incorporated BisAM in the core and the amount of AM during chain extension have been systematically varied. Core structures were achieved by incorporation of total monomer ratios [BisAM]/[AM] ranging from 0.010 to 0.143 . The obtained macromolecular chain transfer agents had weight average molecular weights in the range of $(2.2-7.8) \times 10^{3} \mathrm{Da}$ and polydispersity indices between 1.2 and 15.1. Kinetic experiments were performed to investigate the extent of control of polymerization. Finally, the expansion of the core structures by chain-extension polymerization resulted in the successful preparation of high molecular weight SB-PAMs with apparent molecular weights ranging from 19 to $1250 \mathrm{kDa}$.

\section{INTRODUCTION}

Polyacrylamide (PAM) and its derivatives are widely used in cosmetics, biomedical applications, and wastewater treatment, amongst others. ${ }^{1-3}$ Hereby, the main purpose (mostly in aqueous solution) of the polymer is to enhance the solution viscosity and consequently to improve its rheological properties. ${ }^{4}$ Nowadays, however, there is an increasing demand for more specific polymer structures with even higher complexity. ${ }^{5}$ In that matter, complex polymeric structures consisting of different designs and molecular architectures including block, graft, brush, star, and hyperbranched (hb) polymers have attracted much attention. ${ }^{6,7}$ Specifically interesting are star, branched, and hb polymers, because of their unique rheological and physical properties in aqueous solutions compared to their linear analogues. ${ }^{6,8-11}$ Traditional synthetic routes such as free-radical, anionic, cationic, and group transfer polymerizations are unsatisfactory, in particular, to prepare unconventional PAMs, because stringent control over reagent purity and reaction conditions is indispensable. ${ }^{7}$ In fact, the reactions are characterized by low control over the molecular weight distribution (MWD) and chain architecture. ${ }^{12}$ In contrast, however, living/controlled radical polymerization techniques, such as atom transfer radical polymerizations (ATRP), ${ }^{4,13-16}$ nitroxide-mediated polymerization, ${ }^{17,18}$ and reversible addition fragmentation chain transfer (RAFT) polymerization, ${ }^{19}$ amongst others, ${ }^{20}$ have proven to be versatile in synthesizing a wide range of polymer architectures. ${ }^{21-24}$ Star or starlike copolymers have been studied extensively and are well documented in the literature. ${ }^{11,22,25,26}$ When preparing the materials from multifunctional initiators, ${ }^{15}$ the final product is very well characterized. However, for industrial upscaling, this might not be the most suitable approach because of the high cost of such molecules. In this context, the use of a bifunctional monomer and thus the core/arm approach is much more attractive. The preparation of such architectural structures by RAFT polymerization can be achieved via the "arm-first" (AF) or "core-first" (CF) approach ${ }^{24,27,28}$ or via combinations. ${ }^{29}$ In the AF approach, linear polymer chains are first synthesized and later attached to a core via copolymerization with a divinyl comonomer. ${ }^{27,30}$ In contrast, the CF approach makes use of a multifunctional initiator, which is commonly referred to as the macro chain transfer agent (mCTA) or macro RAFT agent. ${ }^{22}$ Those hb-cores are formed by cross-linkage of the monomer and comonomer [a cross-linker or a branching agent (BA)] in each repeating unit, ${ }^{6}$ while the RAFT functionality remains within the core moiety. ${ }^{23,31}$ The process is driven by intermolecular reactions between the chain-end radicals and the pendant double bonds, ${ }^{26}$ which in turn generates "randomly" branched polymers. ${ }^{27,32}$ Consequently, the core (macro RAFT agent) is further used to synthesize starlike

Received: November 14, 2018

Accepted: December 18, 2018

Published: December 28, 2018 
Table 1. Copolymerization Characteristics of AM and BisAM via RAFT, Forming the Macro RAFT Agent

\begin{tabular}{|c|c|c|c|c|c|c|c|c|}
\hline entry & {$[\mathrm{AM}]_{0} /[\mathrm{BisAM}]_{0} /[\mathrm{CTA}]_{0} /[\mathrm{I}]_{0}{ }^{a}$} & $\begin{aligned} \mathrm{M} / \mathrm{s} 1 / \mathrm{s} 2^{b} & (\mathrm{wt} / \mathrm{vol} / \mathrm{vol}) ; \mathrm{T}\left({ }^{\circ} \mathrm{C}\right) ; \\
& \text { time (min) }\end{aligned}$ & $\begin{array}{c}\text { conv. } \\
(\%)\end{array}$ & $\begin{array}{l}{[M]_{\mathrm{n}, \text { theor. }}{ }^{c}} \\
(-)\end{array}$ & $\begin{array}{l}{[M]_{\mathrm{n}, \mathrm{GPC}}} \\
(-)\end{array}$ & $\begin{array}{l}\text { PDI } \\
(-)\end{array}$ & $\begin{array}{l}\text { solubility in } \\
\text { water }^{e}\end{array}$ & $\begin{array}{l}\text { theor. solid content } \\
\qquad(\mathrm{g} / \mathrm{mL})\end{array}$ \\
\hline 1 & $99: 1: 6.2: 3.1$ & $1: 4: 4 ; 70 ; 120$ & 91.2 & 1319 & 2287 & 1.2 & ++ & 0.105 \\
\hline 2 & $98: 1: 3.1: 1.5$ & $1: 4: 4 ; 70 ; 240$ & 87.5 & 2277 & 3225 & 1.3 & ++ & 0.101 \\
\hline 3 & 49:1:1.6:0.8 & $1: 4: 4 ; 70 ; 270$ & 99.4 & 2582 & 3781 & 1.6 & ++ & 0.114 \\
\hline 4 & 39:1:1.3:0.6 & $1: 4: 4 ; 70 ; 150$ & 98.3 & 2569 & 4088 & 1.7 & ++ & 0.112 \\
\hline 5 & $29: 1: 0.9: 0.5$ & $1: 4: 4 ; 70 ; 120$ & 99.7 & 2624 & 4410 & 1.9 & ++ & 0.113 \\
\hline 6 & $24: 1: 0.8: 0.4$ & $1: 4: 4 ; 70 ; 105$ & 96.7 & 2579 & 4668 & 2.2 & ++ & 0.109 \\
\hline 7 & $19: 1: 0.6: 0.3$ & $1: 4: 4 ; 70 ; 105$ & 94.0 & 2535 & 5446 & 3.2 & ++ & 0.105 \\
\hline 8 & $17: 1: 0.5: 0.3$ & $1: 4: 4 ; 70 ; 100$ & 93.8 & 2545 & 6116 & 4.5 & ++ & 0.104 \\
\hline 9 & $14: 1: 0.5: 0.2$ & $1: 4: 4 ; 70 ; 100$ & 93.7 & 2567 & 7305 & 7.4 & ++ & 0.102 \\
\hline 10 & $11: 1: 0.4: 0.2$ & $1: 4: 4 ; 70 ; 100$ & 92.3 & 2568 & 7750 & 15.1 & ++ & 0.099 \\
\hline 11 & $9: 1: 0.3: 0.2$ & $1: 4: 4 ; 70 ; 120$ & 95.4 & 2696 & $d$ & $d$ & + & 0.100 \\
\hline 12 & $7: 1: 0.2: 0.1$ & $1: 4: 4 ; 70 ; 120$ & 92.8 & 2693 & $d$ & $d$ & + & 0.095 \\
\hline $13^{f}$ & 7:0:0.2:0.1 & $1: 5: 5 ; 70 ; 180$ & 98.4 & 2499 & 2931 & 1.3 & ++ & 0.098 \\
\hline
\end{tabular}

${ }^{a}$ Molar ratio. ${ }^{b} \mathrm{M} / \mathrm{s} 1 / \mathrm{s} 2=$ monomer/solvent $1 /$ solvent $2=\mathrm{AM} /$ buffer solution $(\mathrm{pH}=5) /$ demineralized water. ${ }^{c} \mathrm{Calculated}$ from the linear equivalent theoretical molecular weight formula proposed by Stenzel et al. ${ }^{35}$ using eq $1 .{ }^{d}$ MWD could not be accurately defined by GPC (see text for explanation). ${ }^{e}$ Legend: ++ giving a transparent solution, + giving a slightly cloudy solution. ${ }^{f}$ Linear macro RAFT agent, synthesized under similar conditions in the absence of BisAM.

Table 2. Chain Extension Polymerization of AM with the Macro RAFT Agent under Different Levels of AM Addition

\begin{tabular}{|c|c|c|c|c|c|c|c|c|}
\hline entry & $\begin{array}{c}\mathrm{mCTA}^{d} \\
{[\mathrm{BisAM}]_{0} /[\mathrm{AM}]_{0}}\end{array}$ & {$[\mathrm{M}]_{0} /[\mathrm{mCTA}]_{0} /[\mathrm{I}]_{0}{ }^{a}$} & $\mathrm{M} / \mathrm{sl}^{b}(\mathrm{wt} / \mathrm{vol}) ; T\left({ }^{\circ} \mathrm{C}\right) ;$ time & $\begin{array}{c}\text { conv. } \\
(\%)\end{array}$ & $\begin{array}{l}{[M]_{\mathrm{n}, \text { theor. }}{ }^{c}} \\
(-)^{c}\end{array}$ & $\begin{array}{c}{[M]_{\mathrm{n}, \mathrm{GPC}}} \\
(-)\end{array}$ & $\begin{array}{l}\text { PDI } \\
(-)\end{array}$ & $\begin{array}{l}\text { theor. solid content } \\
\qquad(\mathrm{g} / \mathrm{mL})\end{array}$ \\
\hline 1 & $1: 99$ & $428: 2.7: 1$ & $1: 80 ; 80 ; 295$ & 81.6 & 11616 & 19120 & 1.31 & 0.01 \\
\hline 2 & $1: 98$ & $8216: 1.8: 1$ & $1: 4 ; 80 ; 49$ & 85.4 & 277442 & 352900 & 1.59 & 0.21 \\
\hline 3 & $1: 49$ & 8574:1.6:1 & $1: 4 ; 80 ; 47$ & 88.6 & 338174 & 378500 & 1.82 & 0.22 \\
\hline 4 & $1: 39$ & $10955: 1.9: 1$ & $1: 4 ; 80 ; 49$ & 84.9 & 351198 & 460500 & 1.60 & 0.21 \\
\hline 5 & $1: 29$ & $10955: 1.8: 1$ & $1: 4 ; 80 ; 76$ & 89.9 & 401148 & 476000 & 1.70 & 0.22 \\
\hline 6 & $1: 24$ & 11 598:1.8:1 & $1: 4 ; 80 ; 61$ & 89.4 & 420263 & 504100 & 1.77 & 0.22 \\
\hline 7 & $1: 19$ & 14 085:1.9:1 & $1: 4 ; 80 ; 50$ & 84.3 & 458913 & 491200 & 1.71 & 0.21 \\
\hline 8 & $1: 17$ & $17924: 2.1: 1$ & $1: 4 ; 80 ; 50$ & 82.7 & 512149 & 544400 & 1.64 & 0.21 \\
\hline 9 & $1: 14$ & $16432: 1.6: 1$ & $1: 4 ; 80 ; 95$ & 74.9 & 552253 & 514100 & 1.57 & 0.19 \\
\hline 10 & $1: 11$ & $17927: 1.6: 1$ & $1: 4 ; 80 ; 120$ & 89.1 & 698364 & 573100 & 1.63 & 0.22 \\
\hline 11 & $1: 9$ & 9859:0.9:1 & $1: 4 ; 80 ; 40$ & 88.5 & 727683 & 761000 & 1.46 & 0.22 \\
\hline 12 & $1: 14$ & $26290: 1.3: 1$ & $1: 6 ; 80 ; 165$ & 76.8 & 1127195 & 829000 & 1.46 & 0.13 \\
\hline 13 & $1: 11$ & $26291: 1.2: 1$ & $1: 6 ; 80 ; 135$ & 89.2 & 1387428 & 990900 & 1.40 & 0.15 \\
\hline 14 & $1: 9$ & $28167: 1.2: 1$ & $1: 6 ; 80 ; 60$ & 80.4 & 1317686 & 1003000 & 1.34 & 0.13 \\
\hline 15 & $1: 7$ & $26290: 0.7: 1$ & $1: 6 ; 80 ; 40$ & 83.5 & 2186704 & 1250000 & 1.34 & 0.14 \\
\hline 16 & $1: 14$ & $39434: 1.3: 1$ & $1: 6 ; 80 ; 150$ & 88.8 & 1954299 & 1243000 & 1.37 & 0.15 \\
\hline 17 & $1: 11$ & 39 433:1.2:1 & $1: 6 ; 80 ; 90$ & 82.3 & 1917810 & 1142000 & 1.35 & 0.14 \\
\hline 18 & $1: 9$ & 39 434:1.1:1 & $1: 6 ; 80 ; 120$ & 86.1 & 2111936 & 1072000 & 1.57 & 0.14 \\
\hline 19 & 0 & $56249: 1.1: 1$ & $1: 10 ; 80 ; 86$ & 67.2 & 2365525 & 1143000 & 1.45 & 0.07 \\
\hline
\end{tabular}

${ }^{a}$ Molar ratio. ${ }^{b} \mathrm{M} / \mathrm{s} 1=$ monomer/solvent $1=\mathrm{AM} /$ buffer solution $(\mathrm{pH}=5) .{ }^{c}$ Calculated from the linear equivalent theoretical molecular weight formula proposed by Stenzel et al. using eq $1 .{ }^{d}$ Parent macro RAFT agent (mCTA) ratio of [BisAM]/[AM] from Table 1.

polymers by chain extension with conventional vinyl monomers [acrylic acid or acrylamide (AM)] in the presence of multifunctional RAFT agents. ${ }^{32}$ Recently, the preparation of $\mathrm{hb}$ polymers as core moieties has been reported via RAFT copolymerization of di(ethylene glycol) methacrylate and ethylene glycol diacrylate as the BA in the presence of benzyl pentanoate as the CTA. ${ }^{33}$ Similarly, Perrier et al. documented the synthesis of "core-first" branched polymers by using ethylene glycol dimethacrylate as a cross-linker and different vinyl monomers. ${ }^{30}$

In this article, we report our results on the investigation on the RAFT copolymerization of AM with $N, N^{\prime}$-methylenebis(acrylamide) (BisAM) as the BA, followed by chain extension with different levels of AM addition to obtain water-soluble starlike branched polyacrylamides (SB-PAMs). Detailed experimental work on the effect of the synthesized branched molecular architectures and the degree of branching in relation to rheology is shown in a follow-up paper. ${ }^{34}$ In that paper, macromolecular properties of the polymers are related to enhanced oil recovery (EOR) performance and are evaluated in EOR simulations.

\section{EXPERIMENTAL SECTION}

Chemicals. AM (electrophoresis grade, $\geq 99 \%$ ), BisAM ( $\geq 99 \%$ ), 4,4'-azobis(4-cyanovaleric acid) (ACVA, $\geq 98.0 \%$ ), cyclooctane $(\geq 99.5 \%)$, and sodium chloride $(\mathrm{NaCl}, \geq 99 \%)$ were purchased from Sigma-Aldrich and used as received. 3(((Benzylthio)carbonothioyl)thio)propanoic acid (BCPA) was synthesized according to the literature. ${ }^{8,35}$ However, further purification of BCPA was performed by recrystallization twice from dichloromethane, obtaining the RAFT agent as a yellow 


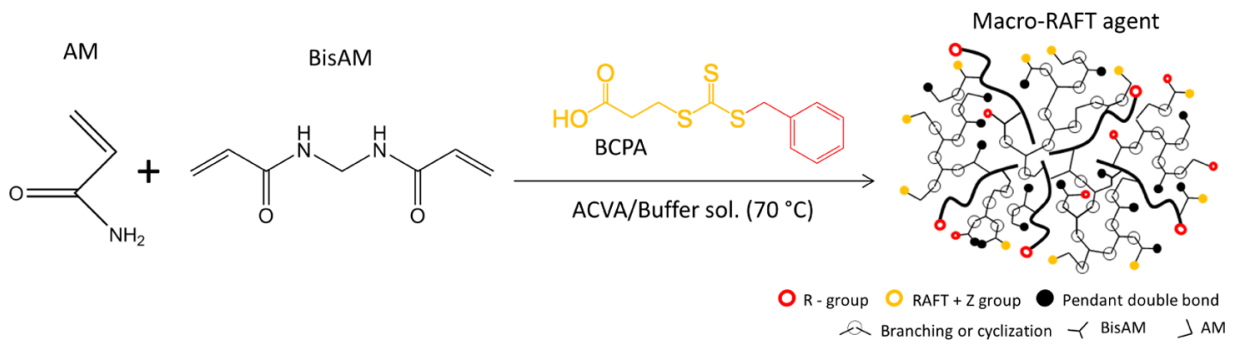

Figure 1. Copolymerization of AM and BisAM to form a core-like macro RAFT agent.

solid powder with $66 \%$ yield. All other chemicals were of reagent grade and used without further purification.

Synthesis of the Macro RAFT Agent (mCTA). A $25 \mathrm{~mL}$ round-bottomed flask was charged with the acrylamide monomer, AM (e.g., Table 1, entry 1: 0.5783 g, 8.136 $\mathrm{mmol}$ ), divinyl monomer, BisAM (0.0128 g, $0.083 \mathrm{mmol})$, RAFT agent, BCPA (0.0703 g, $0.258 \mathrm{mmol})$, and initiator, ACVA (0.0358 g, $0.128 \mathrm{mmol}$ ) (in that order). The monomers, RAFT agent, and initiator were dissolved in a mixture of sodium acetate/acetic acid buffer solution $(\mathrm{pH}=5)$ and ethanol $(50: 50 \mathrm{vol} \%)$ before addition to the reaction mixture. The use of this solvent ensures the solubility of all components. After addition of a magnetic stirrer, the system was degassed by purging with nitrogen gas $\left(\mathrm{N}_{2}\right)$ for at least 30 min under vigorous stirring $(1050 \mathrm{rpm})$ and subsequently sealed. After deoxygenation, the system was placed in an oil bath at $70{ }^{\circ} \mathrm{C}$ to initiate polymerization. All reactions were performed under nitrogen. After a given reaction time, the mixture was exposed to ambient air and diluted with demineralized water $(5 \mathrm{~mL})$ to terminate the reaction. A sample of $0.3 \mathrm{~mL}$ was taken from the solution mixture for determination of AM conversion by gas chromatography (GC) and the molecular weight and weight distribution by gel permeation chromatography (GPC). To isolate the polymerized macro RAFT agent, the solvent (buffer solution/ ethanol mixture) was evaporated at low pressure ( $<100 \mathrm{mbar})$. The yellowish, gel-like product was dissolved in sufficient demineralized water (typically a few drops). Afterward, the reaction mixture was precipitated in an excess amount of methanol. Hereafter, the precipitated product was decanted and filtered over a $0.45 \mu \mathrm{m}$ filter element by using a vacuum pump. The solid residue was then dried in an oven at $70{ }^{\circ} \mathrm{C}$. The detailed reaction conditions for the synthesis of the macro RAFT agent are summarized in Table 1. The linear mCTA (entry 13) was synthesized under similar conditions. GPC traces of the obtained macro RAFT agents are reported in the Supporting Information file.

SB-PAM Polymerization. A $250 \mathrm{~mL}$ three-necked flask was charged with the macro RAFT agent (e.g. Table 2, entry 1: $0.0502 \mathrm{~g}, 0.156 \mathrm{mmol})$, monomer, AM (5.0009 g, $0.070 \mathrm{~mol})$, and initiator, ACVA $(0.0024 \mathrm{~g}, 0.086 \mathrm{mmol})$ which were dissolved in sodium acetate/acetic acid buffer solution (20 $\mathrm{mL})$ at $\mathrm{pH}=5$. Subsequently, the system was purged with nitrogen gas $\left(\mathrm{N}_{2}\right)$ under vigorous stirring $(1050 \mathrm{rpm})$ for at least $30 \mathrm{~min}$. After degassing, the system was placed in an oil bath at $80{ }^{\circ} \mathrm{C}$ to initiate the reaction. All reactions were performed under nitrogen. During the reaction, the mixture of the reactants transitioned from yellowish to a whitish gelatinelike homogeneous paste. The viscosity of the solution visibly increased with time. After a given reaction time, the mixture was exposed to ambient air and diluted with demineralized water to terminate the reaction. A sample of $0.3 \mathrm{~mL}$ was taken from the reaction mixture for the determination of $\mathrm{AM}$ conversion by GC and the molecular weight and weight distribution by GPC. Afterward, the product was precipitated by washing the polymer in an excess amount of methanol. Subsequently, the precipitated polymer was decanted and dried in an oven at $70{ }^{\circ} \mathrm{C}$. The linear polymer (entry 19) was synthesized under similar conditions.

Characterization. AM conversion was determined using GC. Hereby, the reaction mixture samples $(0.3 \mathrm{~mL})$ were precipitated in acetone solution with $1000 \mathrm{ppm}$ of pentadecane (reference). The precipitated polymer solution was filtered to remove the solid and injected on a Hewlett Packard 5890 GC system with an Elite-Wax ETR column. The theoretical molecular weight $\left(M_{\text {theor. }}\right)$ was calculated, according to the literature, ${ }^{12,22,35}$ as follows

$$
\begin{aligned}
M_{\text {theor. }}= & \left(\frac{[M]_{0, \mathrm{AM}}}{[M]_{0, \mathrm{RAFT}}} \cdot[M]_{\mathrm{AM}}+\frac{[M]_{0, \mathrm{BisAM}}}{[M]_{0, \mathrm{RAFT}}} \cdot[M]_{\mathrm{BisAM}}\right) \cdot X \\
& +[M]_{\mathrm{RAFT}}
\end{aligned}
$$

where $M_{\text {theor. }}$ is the theoretical molecular weight of the synthesized polymer, $M_{0, \mathrm{AM}}$ and $M_{0, \mathrm{BisAM}}$ are the initial monomer concentration of $\mathrm{AM}$ and BisAM, respectively, (mol), $M_{0, \text { RAFT }}$ is the initial concentration of the RAFT agent (mol), $M_{\mathrm{AM}}$ is the molecular weight of the AM monomer, $M_{\mathrm{BisAM}}$ is the molecular weight of the BisAM monomer, $M_{\mathrm{RAFT}}$ is the molecular weight of the RAFT agent, and $X$ represents the monomer conversion. GPC was performed with an Agilent 1200 system with Polymer Standard Service (PSS) columns (guard, 100 and $3000 \AA ̊, 8 \times 300 \mathrm{~mm}$ ). A $50 \mathrm{mmol}$ sodium nitrate $\left(\mathrm{NaNO}_{3}\right)$ aqueous solution was used as the eluent. GPC samples were dissolved in $50 \mathrm{mM}$ sodium nitrate (with Milli-Q water) prior to injection. The elution was conducted at a flow rate of $1.00 \mathrm{~mL} / \mathrm{min}$ at $40{ }^{\circ} \mathrm{C}$. Linear PAM standards were used for baseline calibration with WinGPC software (PSS) to calculate the apparent molecular weight and polydispersity index (PDI) of the GPC samples. The chemical structure of macroCTA and chain-extended samples was confirmed by ${ }^{1} \mathrm{H}$ NMR. The spectra were recorded on Varian Mercury Plus $400 \mathrm{MHz} . \mathrm{D}_{2} \mathrm{O}$ was used as the solvent.

\section{RESULTS AND DISCUSSION}

Synthesis of the Macro RAFT Agent. The synthesis of the macro RAFT agent, as outlined in Figure 1, was performed by copolymerization of a vinyl monomer (AM) and divinyl comonomer (BisAM) at constant amounts of CTA (BCPA) via RAFT, generating "core-like" branched macromolecular structures (macro RAFT agent). The amount of BisAM was altered by changing the total monomer ratio of [BisAM]/ $[\mathrm{AM}]$, ranging from 0.010 to 0.143 . The $\mathrm{pH}$ was maintained at 
A

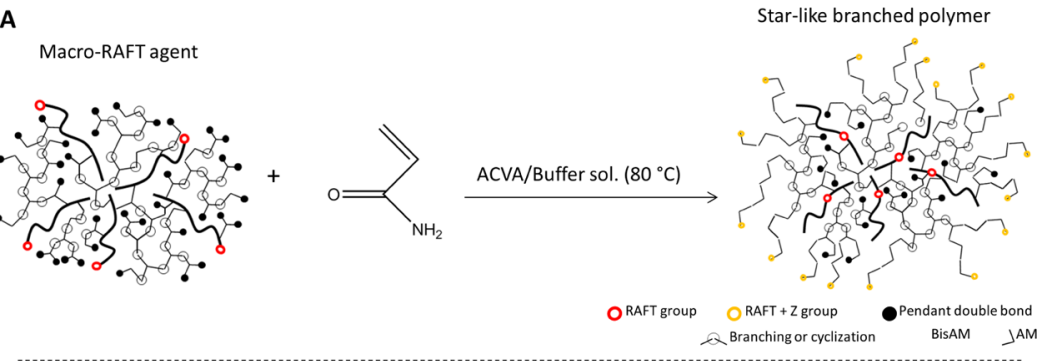

B

Star-like branched polymer growth
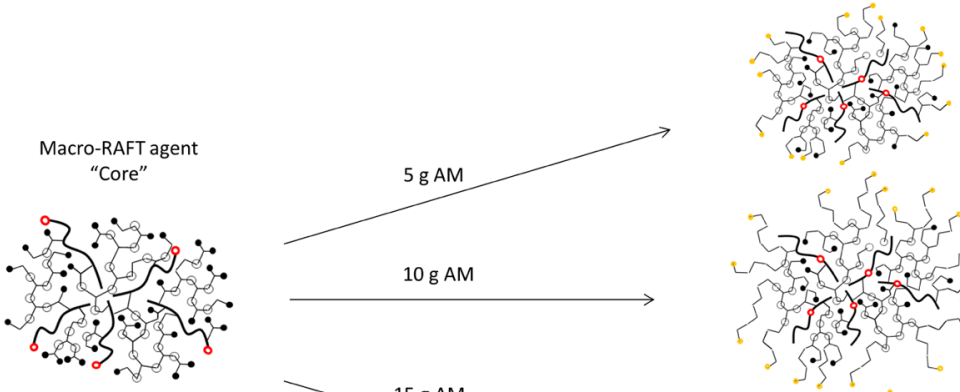
0,350
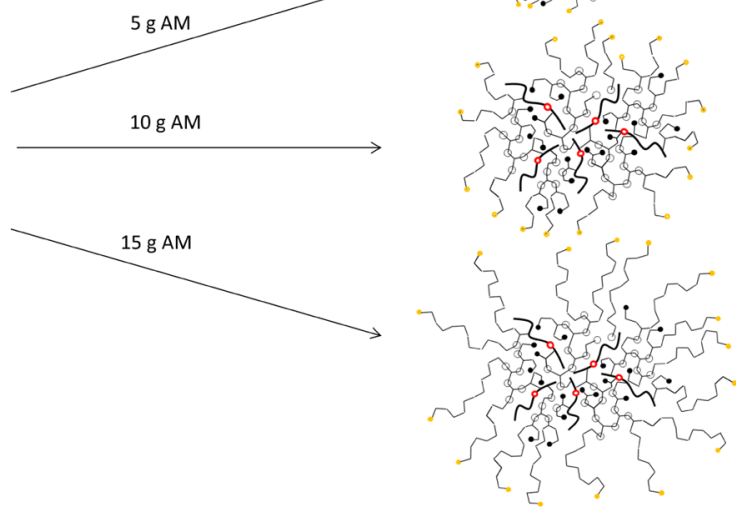

Figure 2. (a) Chain extension polymerization of the macro RAFT agent with AM to form SB-PAMs and (b) visualization of the expected polymer growth with different levels of AM addition.

5 during polymerization to prevent hydrolysis of the CTA. $^{22,23,36}$ The properties of the macro RAFT agent are given in Table 1. For all entries, the ratio of monomer to CTA to initiator, $[\mathrm{AM}+\mathrm{BisAM}] /[\mathrm{CTA}] /[\mathrm{I}]$ was maintained constant at $64 / 2 / 1$, except for entry 1 , where the ratio was 32/2/1. ${ }^{1} \mathrm{H}$ NMR spectra (see Supporting Information) confirm the formation of the PAM macro CTA, evidencing the incorporation of BCPA moieties and residual pendant double bonds from BisAM. Higher initial BisAM/AM ratio resulted in higher amount of pendant double bonds; however, an accurate quantification was not possible because of overlapping and broadening of the peaks. The molecular weight averages $\left(M_{n}\right)$, determined by GPC analysis were between $(2.2$ and 7.8$) \times 10^{3}$ and PDIs were between 1.2 and 15.1 (Table 1). The GPC traces (see Supporting Information) show that the MWD becomes broader and multimodal as the BisAM/AM ratio increases. As it can be noted here, $M_{n, \text { theor. }}$ is always lower than $M_{\mathrm{n}, \mathrm{GPC}}$. The theoretical molecular weight is calculated through the conversion values, based on GC analysis. In this context, the observed differences might be due to the accuracy of both techniques and to the differences in hydrodynamic volumes. Furthermore, some samples have such a high PDI that the average value represents a mere indication. In any case, for the linear polymer (entry 13 in Table 1), the discrepancy is roughly $20 \%$, the lowest among all samples. As suggested by an anonymous reviewer of this work (whom we wish to acknowledge), the systematically higher than calculated $M_{\mathrm{n}}$ can also suggest a not optimal efficiency of the controlling functional groups, resulting in a lower than calculated growing polymer chains and, as a consequence, a higher than calculated molecular weight. This may be ascribed to the engulfing of the reactive chain ends at the early stage of core formation, preventing some of them from effectively reactivating chain growth in the second stage; another option could be some side reactions, such as core-core coupling, resulting in deactivation of a fraction of the RAFT-active groups. This would also be compatible with the increase of PDI with $M_{\mathrm{n}}$ (Table 1). The amount of BisAM, as the BA in the copolymerization system, significantly influenced the branching capability of the prepared macromolecules. The total monomer conversion was high throughout all experiments with average values of $94.6 \pm 3.6 \%$. Similar observations were reported by Vo and co-workers, ${ }^{37}$ Perrier's group, ${ }^{30}$ Wang et al., ${ }^{27,38}$ and Taton et al., ${ }^{32}$ amongst others. ${ }^{39-41}$ The cross-linker concentration shows a substantial effect on the growth of molar mass of the branched copolymers. From the results, it can be seen that the deviation from an apparent linear equivalent molecular weight increases and broader MWDs occur at increased BA, suggesting prominent branching and/or cyclization reactions. ${ }^{38}$ Previously published articles report that with significantly more than one divinyl comonomer per chain (high BA), macrogelation occurs. $^{30,32,37,42}$ However, this is only valid at fixed CTA values. In fact, it is frequently reported in the literature that much higher BA content can be incorporated into the polymeric structure when $[\mathrm{CTA}] /[\mathrm{BA}]$ ratios $>0.5$ are used to effectively suppress the macrogelation process. ${ }^{6,37,42-46}$ In this context, $\mathrm{Li}$ et al. investigated the effect of the critical overlap concentration $\left(C^{*}\right)$ of polymers on cyclization by preparation of watersoluble cationic branched copolymers via quaternization. ${ }^{47}$ The latter concentration is the threshold for interaction or overlapping of the domains of polymer chains and is a function 
of the molecular volume and radius of gyration. ${ }^{48}$ The authors conclude from their model system that intramolecular (primary) cyclization is strongly favored with relatively high proportions of a divinyl comonomer (BA) if the corresponding monomer/polymer concentration is comparable to or lower than $C^{*} .{ }^{47}$ The authors argue that the overlap concentration causes an interpenetration of associating polymeric coils, which in turn favors primary cyclization. The results of several studies, confirm this theory. ${ }^{32,49}$ In the present study, however, all copolymerizations were conducted with 14-15 wt/vol \%, while the estimated $C^{*}$, according to $\mathrm{Li}$ et al., is $5 \mathrm{wt} / \mathrm{vol} \%$ for an $\mathrm{AM} / \mathrm{Bis} A M$ copolymerization system. ${ }^{47}$ In fact, the obtained results can be interpreted in relation to pronounced primary cyclization reactions, causing the broadening of the MWD. Hence, intramolecular cyclization reactions dominated over intermolecular branching reactions at increased BA concentrations.

Synthesis of the SB-PAM Copolymers. The synthesis of SB-PAMs was performed according to Figure 2a, using different amounts of AM (5 g: entry $1-11,10 \mathrm{~g}$ : entry 1215, and 15 g: entry 16-18) (Figure 2b) with the branched macromolecular cores (macro RAFT agents) listed in Table 1. A linear reference polymer (entry 19) was prepared. The experimental conditions are presented in Table 2. Soluble polymers were produced in all entries with maximum achievable monomer conversion of $89.9 \%$ (entry 5). The used mCTA amount was fixed at $0.5 \mathrm{~g}$, whereas the initiator amount for the SB-PAMs was based on $0.5 \mathrm{~mol} \%$ of the specific average molecular weight of the macro RAFT agent because the trithiocarbonate functionality remained in the core. $^{23}$ The experimental molecular weight of entry 1-4 (PDI $<2$ ) was directly determined by the GPC analysis. For entry 5-18, the experimental molecular weight falls outside the measurable range of the GPC and thus could not been determined with reliable accuracy. The GPC is calibrated based on well-defined linear AM standards with $M_{n}$ up to 465 000 , rendering $M_{\mathrm{n}}$ of entries 5-18 outside the range of the calibration standards. Because of these limitations, we can only use the $M_{\mathrm{n}}$ and PDI values obtained by GPC as merely indicatives of a qualitative trend. However, we can observe from Table 2 that in the lower range of $M_{n}$, the measured values are systematically higher than the calculated ones. This is in line with what is observed for the cores and it can be ascribed to the inefficiency of the RAFT controlling groups. As $M_{\mathrm{n}}$ increases well above the column limit, this trend cannot be observed anymore, but it is very likely that GPC significantly underestimates these values. Moreover, the hydrodynamic volume of SB-PAMs is reported to be smaller than their linear counterparts because of the compactness of branched polymers. ${ }^{4}$ Nevertheless, for studying the effect of AM concentration and the effect of the mCTA with more precision, GPC traces are presented for a series of selected SB-polymers, such as entry 2,9,10, and 11 (Figure 3 ), entry 2, 4, 6, 8, and 10 (Figure 4), entry 9, 12, 15, and 16 (see Supporting Information), and entry 16, 17, and 18 (Figure 5).

An increase of incorporated BA (in the core moiety) leads to bimodal weight distributions and more pronounced high molecular weight shoulders (Figure 3: only for entry 9 and 10). This could be due to the fact that the cores with higher BisAM/AM ratio already present multimodal MWD (see Supporting Information file). According to Zhu et al., this effect can also originate from random-branched polymers having randomly distributed primary chains, ${ }^{50}$ while another

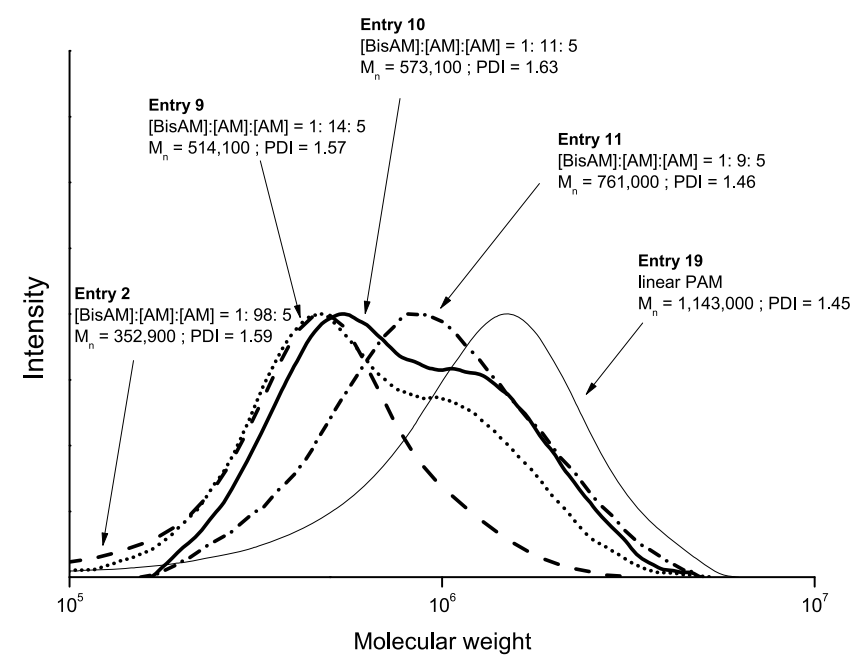

Figure 3. GPC traces of SB-PAMs (compared with a linear PAM), polymerized at constant AM concentration with differently sized macro RAFT agents.

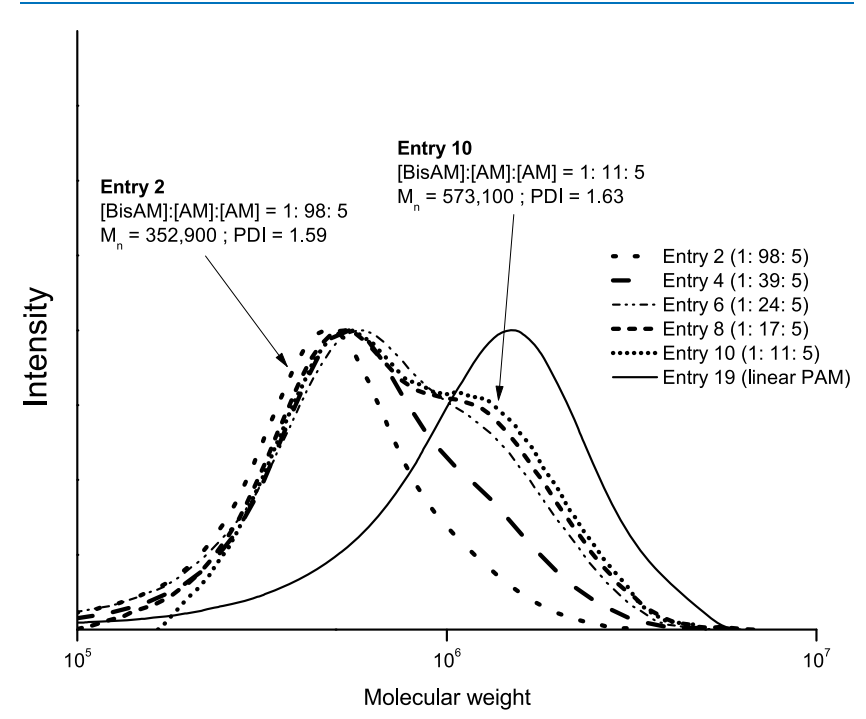

Figure 4. Evolution of the molecular weight shoulder with increasing BA content in the macro RAFT agent and chain-extended at constant AM concentration.

explanation is a star-star coupling reaction (side reaction)..$^{51}$ Star-star coupling is a termination reaction taking place between two free "arm" macro radicals. ${ }^{52}$ The bimodal MWD was reported in comparable studies conducted by Wang et al. ${ }^{27,53}$ The apparent monomodal distribution observed for entries 11-18 could simply be ascribed to higher molecular weight and longer branches. The growth of the molecular weight shoulder (Figure 4) might be related to the increased amount of cross-linker concentration, resulting into more branching points and ultimately causing the double-star by coupling of two PAM arms (long-chain branching ${ }^{52}$ ). ${ }^{27}$ Indeed, all other entries present monomodal MWDs, which in contrast to the former reveals the typical behavior of a starshaped polymer, with randomly distributed primary chains. ${ }^{50}$ Increasing the amount of AM (e.g., entry 12 and 16) favored star polymer formation with higher molecular weights. The MWD seems to become narrower, but because the values of molecular weight obtained for these polymers are higher than the detection limit of the column, these could be artifacts. As a 


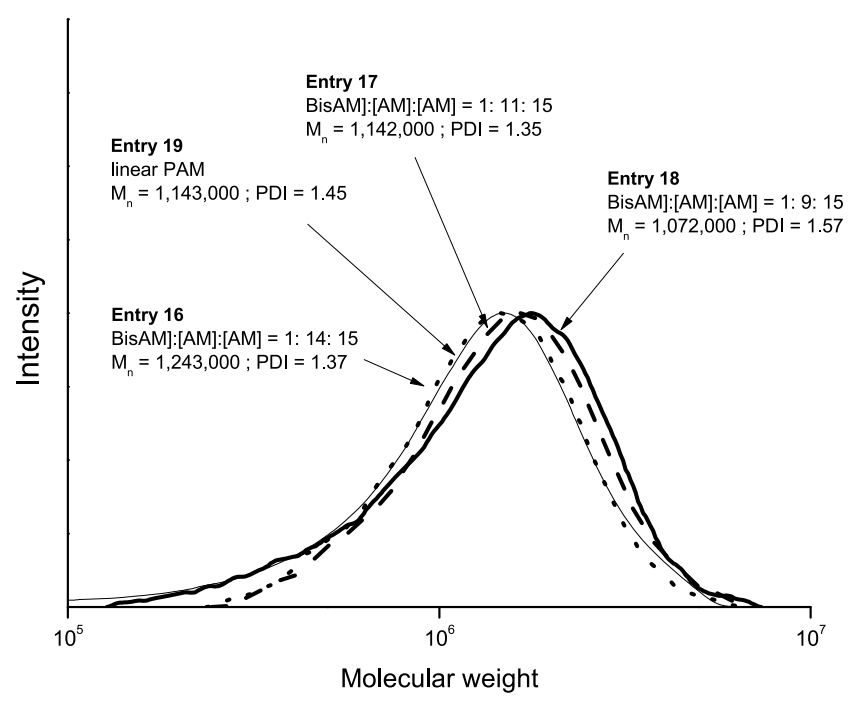

Figure 5. GPC traces of SB-PAMs (compared with a linear PAM), polymerized with the largest sized macro RAFT agents (highest concentration of $\mathrm{BA}$ ) with the highest level of AM addition. confirmation of the reached limit for the column, apparent molecular weights for entries 16-19 are very similar (Figure 5). Fröhlich and co-workers studied possible shielding effects on the formation of star-shaped polymers via RAFT polymerization. Besides the common steric congestion, ${ }^{51}$ the authors documented that steric crowding (expansion of the core) can be of significance. Consequently, the formation of longer chains around the core, as well as the compactness of the core causes termination reactions. ${ }^{54}$ In theory, cores with higher BA content should form systems with a higher number of branches, but because of the mentioned crowding and termination (also evidenced by broader MWD), probably less and longer chains are formed. To further investigate the kinetics of polymerization, an experiment with $0.7 \mathrm{~mol} \mathrm{AM}$ and a macro RAFT (core moiety) containing a BisAM/AM ratio of 1:11 was performed. In Figure 6a, the monomer conversion, PDI, and molecular weight GPC are displayed, while in Figure $6 \mathrm{~b}$, the pseudo first-order kinetic plot for polymerization is illustrated. From Figure 6b, nonlinearity can be observed, which indicates the occurrence of termination reactions. ${ }^{55}$ Given the conditions of the experiment and taking into account previously obtained results, the nonlinearity as well as

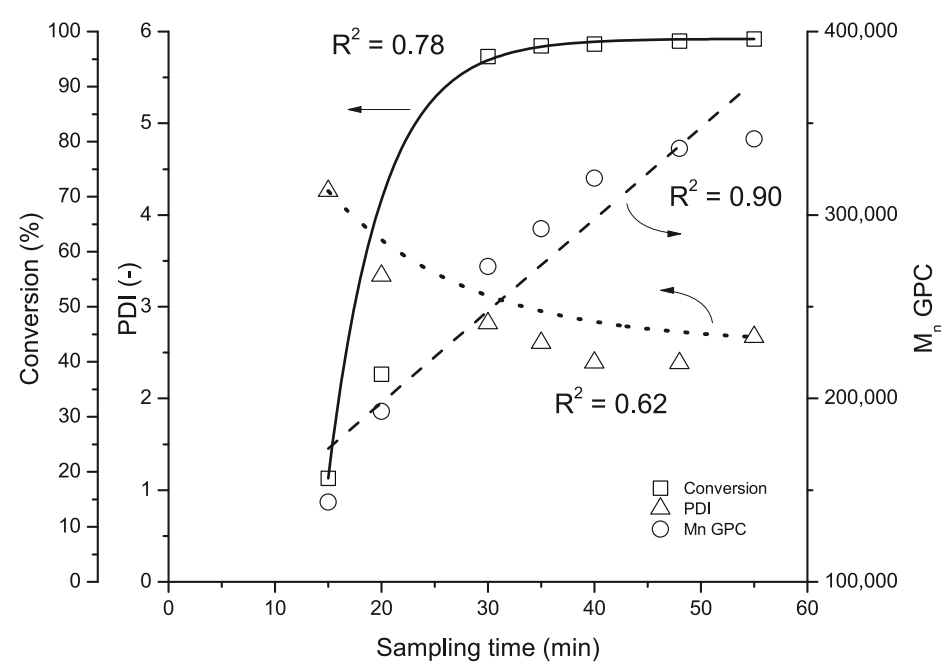

(a)

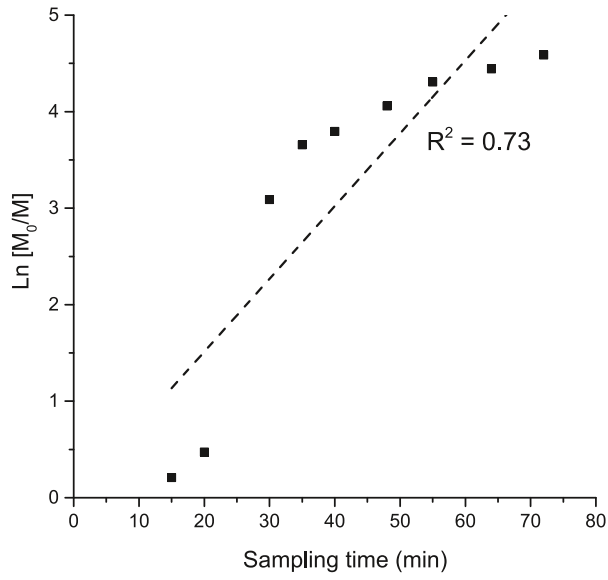

(b)

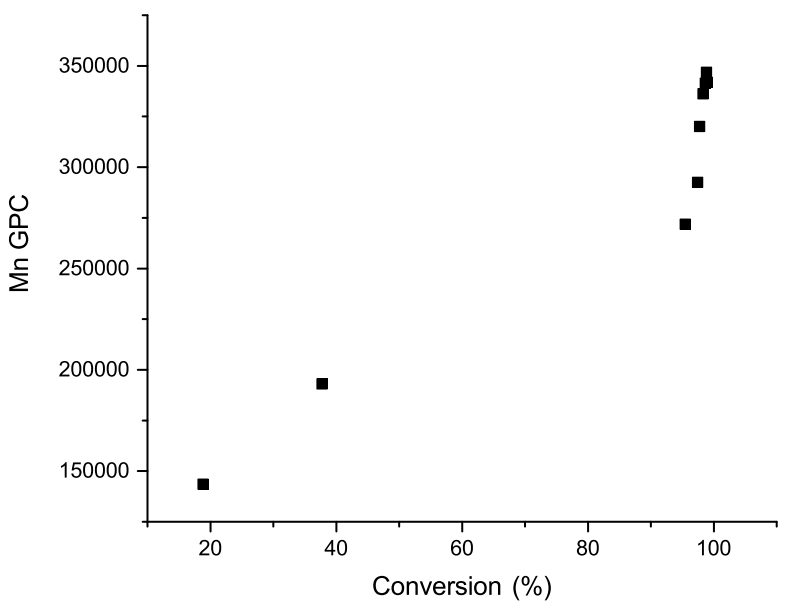

(c)

Figure 6. (a) Dependency of conversion, PDI, and $M_{\mathrm{n}}$ on the sampling time. (b) Pseudo first-order kinetic plot for the RAFT chain extension polymerization of the macro RAFT agent with AM. (c) $M_{\mathrm{n}, \mathrm{GPC}}$ vs conversion for the kinetic experiment. 
the increase of $M_{n}$ at constant conversion (Figure 6c) probably arises from star-star coupling reactions. The kinetic data, together with the GPC traces (Figure 7), showing the

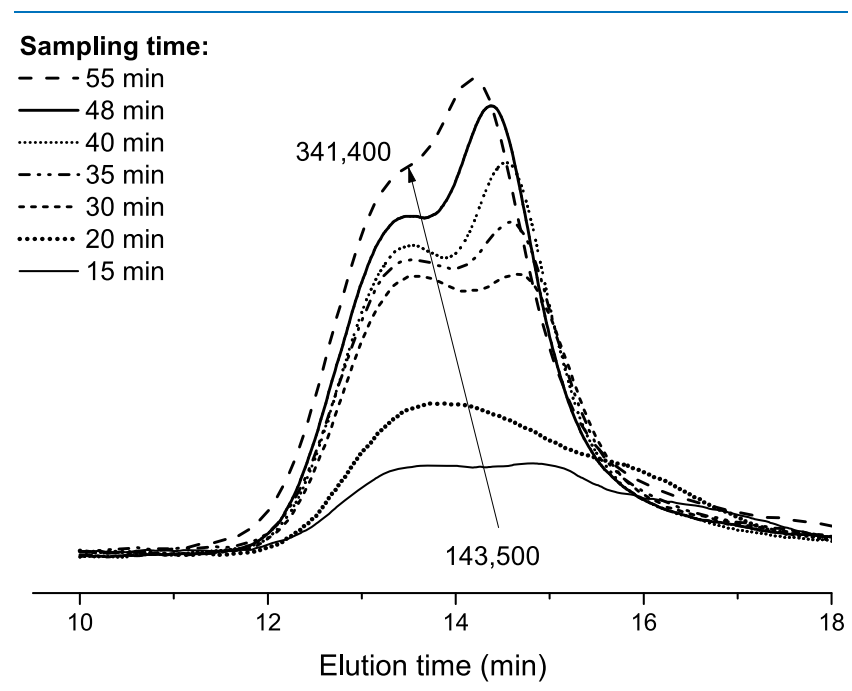

Figure 7. Evolution of GPC traces for the kinetic experiment.

development of bimodal distribution during polymerization, suggest that, even though the PDI remains narrow (and actually decreases) with conversion, polymerization is not a completely controlled process, in line with previously reported synthesis of hb polymers via RAFT. ${ }^{30}$

\section{CONCLUSIONS}

SB-PAMs have been successfully prepared by RAFT copolymerization of AM with BisAM as BA, in the presence of a CTA BCPA followed by RAFT chain extension with various levels of AM. The BA was effectively incorporated into the core moiety with total monomer ratios [BisAM]/[AM] ranging from 0.010 to 0.143 . The obtained macromolecular branched cores (mCTA) had weight average molecular weights in the range of $(2.2-7.8) \times 10^{3} \mathrm{Da}$ and PDIs between 1.2 and 15.1 at high monomer conversions of $94.6 \pm 3.6 \%$. The increasing PDI value is argued to be the result of dominant intramolecular cyclization reactions due to increased BA concentration. Chain extension polymerization with varied levels of AM showed that an increase in the monomer (AM) to macro RAFT agent (mCTA) ratio results in higher average molecular weights with high monomer conversions. GPC traces elucidated the formation of high molecular weight shoulders, as a result of star-star coupling reactions of two PAM arms. Detailed experimental work on the effect of the synthesized branched molecular architectures and the degree of branching in relation to rheology is shown in a follow-up paper. $^{34}$ There, macromolecular properties of the polymers are related to EOR performance and are evaluated in EOR simulations.

\section{ASSOCIATED CONTENT}

\section{S Supporting Information}

The Supporting Information is available free of charge on the ACS Publications website at DOI: 10.1021/acsomega.8b03178.

GPC traces of different SB-PAMs versus linear PAM; GPC traces of different macro-RAFT agents (SB-PAM core); and ${ }^{1} \mathrm{H}$ NMR traces of different macro-RAFT agents (SB-PAM core) (PDF)

\section{AUTHOR INFORMATION}

\section{Corresponding Author}

*E-mail: p.raffa@rug.nl (P.R.).

ORCID 1

Francesco Picchioni: 0000-0002-8232-2083

Patrizio Raffa: 0000-0003-0738-3393

Notes

The authors declare no competing financial interest.

\section{ACKNOWLEDGMENTS}

This research forms part of the research program of the Dutch Polymer Institute, Project 778.

\section{REFERENCES}

(1) Wever, D. A. Z.; Picchioni, F.; Broekhuis, A. A. Polymers for enhanced oil recovery: A paradigm for structure-property relationship in aqueous solution. Prog. Polym. Sci. 2011, 36, 1558-1628.

(2) Shalaby, S. W.; McCormick, C. L.; Butler, G. B. Water-Soluble Polymers: Synthesis, Solution Properties, and Applications; American Chemical Society, 1991.

(3) Boyer, C.; Bulmus, V.; Davis, T. P.; Ladmiral, V.; Liu, J.; Perrier, S. Bioapplications of RAFT polymerization. Chem. Rev. 2009, 109, 5402-5436.

(4) Wever, D. A. Z.; Polgar, L. M.; Stuart, M. C. A.; Picchioni, F.; Broekhuis, A. A. Polymer molecular architecture as a tool for controlling the rheological properties of aqueous polyacrylamide solutions for enhanced oil recovery. Ind. Eng. Chem. Res. 2013, 52, 16993-17005.

(5) Carlmark, A.; Hawker, C.; Hult, A.; Malkoch, M. New methodologies in the construction of dendritic materials. Chem. Soc. Rev. 2009, 38, 352-362.

(6) Voit, B. I.; Lederer, A. Hyperbranched and Highly Branched Polymer Architectures-Synthetic Strategies and Major Characterization Aspects. Chem. Rev. 2009, 109, 5924-5973.

(7) Thomas, D. B.; Convertine, A. J.; Myrick, L. J.; Scales, C. W.; Smith, A. E.; Lowe, A. B.; Vasilieva, Y. A.; Ayres, N.; McCormick, C. L. Kinetics and Molecular Weight Control of the Polymerization of Acrylamide via RAFT †. Macromolecules 2004, 37, 8941-8950.

(8) Jesberger, M.; Barner, L.; Stenzel, M. H.; Malmström, E.; Davis, T. P.; Barner-Kowollik, C. Hyperbranched polymers as scaffolds for multifunctional reversible addition-fragmentation chain-transfer agents: A route to polystyrene-core -polyesters and polystyreneblock -poly(butyl acrylate)-core -polyesters. J. Polym. Sci., Part A: Polym. Chem. 2003, 41, 3847-3861.

(9) Jiménez-Regalado, E. J.; Cadenas-Pliego, G.; Pérez-Álvarez, M.; Hernández-Valdez, Y. Study of three different families of watersoluble copolymers: synthesis, characterization and viscoelastic behavior of semidilute solutions of polymers prepared by solution polymerization. Polymer 2004, 45, 1993-2000.

(10) Gao, C.; Yan, D. Hyperbranched polymers: from synthesis to applications. Prog. Polym. Sci. 2004, 29, 183-275.

(11) Tuncer, C.; Bütün, V. Highly cross-linked soluble star copolymers with well controlled molecular weights. Eur. Polym. J. 2015, 67, 292-303.

(12) Favier, A.; Charreyre, M.-T. Experimental Requirements for an Efficient Control of Free-Radical Polymerizations via the Reversible Addition-Fragmentation Chain Transfer (RAFT) Process. Macromol. Rapid Commun. 2006, 27, 653-692.

(13) Matyjaszewski, K.; Xia, J. Atom transfer radical polymerization. Chem. Rev. 2001, 101, 2921-2990.

(14) Wever, D. A. Z.; Picchioni, F.; Broekhuis, A. A. Branched polyacrylamides: Synthesis and effect of molecular architecture on solution rheology. Eur. Polym. J. 2013, 49, 3289-3301. 
(15) Wever, D. A. Z.; Riemsma, E.; Picchioni, F.; Broekhuis, A. A. Comb-like thermoresponsive polymeric materials: Synthesis and effect of macromolecular structure on solution properties. Polymer 2013, 54, 5456-5466.

(16) Wever, D. A. Z.; Raffa, P.; Picchioni, F.; Broekhuis, A. A. Acrylamide Homopolymers and Acrylamide-N-Isopropylacrylamide Block Copolymers by Atomic Transfer Radical Polymerization in Water. Macromolecules 2012, 45, 4040-4045.

(17) Fischer, H. The persistent radical effect: a principle for selective radical reactions and living radical polymerizations. Chem. Rev. 2001, 101, 3581-3610.

(18) Hawker, C. J.; Bosman, A. W.; Harth, E. New polymer synthesis by nitroxide mediated living radical polymerizations. Chem. Rev. 2001, 101, 3661-3688.

(19) Barner-Kowollik, C.; Quinn, J. F.; Morsley, D. R.; Davis, T. P. Modeling the reversible addition-fragmentation chain transfer process in cumyl dithiobenzoate-mediated styrene homopolymerizations: Assessing rate coefficients for the addition-fragmentation equilibrium. J. Polym. Sci., Part A-1: Polym. Chem. 2001, 39, 1353-1365.

(20) Zhang, C.; Zhou, Y.; Liu, Q.; Li, S.; Perrier, S.; Zhao, Y. Facile synthesis of hyperbranched and star-shaped polymers by RAFT polymerization based on a polymerizable trithiocarbonate. Macromolecules 2011, 44, 2034-2049.

(21) Hawker, C. J. Architectural Control in"Living" Free Radical Polymerizations: Preparation of Star and Graft Polymers. Angew. Chem., Int. Ed. Engl. 1995, 34, 1456-1459.

(22) Perrier, S.; Takolpuckdee, P. Macromolecular design via reversible addition-fragmentation chain transfer (RAFT)/xanthates (MADIX) polymerization. J. Polym. Sci., Part A: Polym. Chem. 2005, 43, 5347-5393.

(23) Moad, G.; Rizzardo, E.; Thang, S. H. Living Radical Polymerization by the RAFT Process-A First Update. Aust. J. Chem. 2006, 59, 669-692.

(24) Gregory, A.; Stenzel, M. H. Complex polymer architectures via RAFT polymerization: From fundamental process to extending the scope using click chemistry and nature's building blocks. Prog. Polym. Sci. 2012, 37, 38-105.

(25) Kakwere, H.; Perrier, S. Facile synthesis of star-shaped copolymers via combination of RAFT and ring opening polymerization. J. Polym. Sci., Part A-1: Polym. Chem. 2009, 47, 6396-6408.

(26) Gao, H.; Matyjaszewski, K. Synthesis of functional polymers with controlled architecture by CRP of monomers in the presence of cross-linkers: from stars to gels. Prog. Polym. Sci. 2009, 34, 317-350.

(27) Wang, D.; Wang, W.-J.; Li, B.-G.; Zhu, S. Semibatch RAFT polymerization for branched polyacrylamide production: Effect of divinyl monomer feeding policies. AIChE J. 2012, 59, 1322-1333.

(28) Chaffey-Millar, H.; Stenzel, M. H.; Davis, T. P.; Coote, M. L.; Barner-Kowollik, C. Design criteria for star polymer formation processes via living free radical polymerization. Macromolecules 2006, 39, 6406-6419.

(29) Altintas, O.; Yankul, B.; Hizal, G.; Tunca, U. A3-type star polymers via click chemistry. J. Polym. Sci., Part A-1: Polym. Chem. 2006, 44, 6458-6465.

(30) Liu, B.; Kazlauciunas, A.; Guthrie, J. T.; Perrier, S. One-pot hyperbranched polymer synthesis mediated by reversible addition fragmentation chain transfer (RAFT) polymerization. Macromolecules 2005, 38, 2131-2136.

(31) Gao, H.; Matyjaszewski, K. Modular Approaches to Star and Miktoarm Star Polymers by ATRP of Cross-Linkers. Macromolecular Symposia, 2010; pp 12-16.

(32) Taton, D.; Baussard, J.-F. o.; Dupayage, L.; Poly, J.; Gnanou, Y.; Ponsinet, V.; Destarac, M.; Mignaud, C.; Pitois, C. Water soluble polymeric nanogels by xanthate-mediated radical crosslinking copolymerisation. Chem. Commun. 2006, 1953-1955.

(33) Luzon, M.; Boyer, C.; Peinado, C.; Corrales, T.; Whittaker, M.; Tao, L.; Davis, T. P. Water-soluble, thermoresponsive, hyperbranched copolymers based on PEG-methacrylates: Synthesis, characterization, and LCST behavior. J. Polym. Sci., Part A: Polym. Chem. 2010, 48, 2783-2792.
(34) Klemm, B.; Picchioni, F.; Raffa, P.; van Mastrigt, F. Star-Like Branched Polyacrylamides by RAFT polymerization, Part II: Performance Evaluation in Enhanced Oil Recovery (EOR). Ind. Eng. Chem. Res. 2018, 57, 8835-8844.

(35) Stenzel, M. H.; Davis, T. P. Star polymer synthesis using trithiocarbonate functional ?-cyclodextrin cores (reversible additionfragmentation chain-transfer polymerization). J. Polym. Sci., Part A: Polym. Chem. 2002, 40, 4498-4512.

(36) Thomas, D. B.; Sumerlin, B. S.; Lowe, A. B.; McCormick, C. L. Conditions for Facile, Controlled RAFT Polymerization of Acrylamide in Water. Macromolecules 2003, 36, 1436-1439.

(37) Vo, C.-D.; Rosselgong, J.; Armes, S. P.; Billingham, N. C. RAFT synthesis of branched acrylic copolymers. Macromolecules 2007, 40, $7119-7125$.

(38) Wang, D.; Li, X.; Wang, W.-J.; Gong, X.; Li, B.-G.; Zhu, S. Kinetics and modeling of semi-batch RAFT copolymerization with hyperbranching. Macromolecules 2011, 45, 28-38.

(39) Slark, A. T.; Sherrington, D. C.; Titterton, A.; Martin, I. K. Branched methacrylate copolymers from multifunctional comonomers: the effect of multifunctional monomer functionality on polymer architecture and properties. J. Mater. Chem. 2003, 13, 2711-2720.

(40) Costello, P. A.; Martin, I. K.; Slark, A. T.; Sherrington, D. C.; Titterton, A. Branched methacrylate copolymers from multifunctional monomers: chemical composition and physical architecture distributions. Polymer 2002, 43, 245-254.

(41) Wang, Z.; He, J.; Tao, Y.; Yang, L.; Jiang, H.; Yang, Y. Controlled chain branching by RAFT-based radical polymerization. Macromolecules 2003, 36, 7446-7452.

(42) Li, Y.; Armes, S. P. Synthesis of model primary amine-based branched copolymers by pseudo-living radical copolymerization and post-polymerization coupling of homopolymers. Macromolecules 2009, 42, 939-945.

(43) Rosselgong, J.; Armes, S. P.; Barton, W.; Price, D. Synthesis of highly branched methacrylic copolymers: observation of near-ideal behavior using RAFT polymerization. Macromolecules 2009, 42, 5919-5924.

(44) Tao, L.; Liu, J.; Tan, B. H.; Davis, T. P. RAFT synthesis and DNA binding of biodegradable, hyperbranched poly (2-(dimethylamino) ethyl methacrylate. Macromolecules 2009, 42, 4960-4962.

(45) Poly, J.; Wilson, D. J.; Destarac, M.; Taton, D. Synthesis of Poly(vinyl acetate) Nanogels by Xanthate-Mediated Radical Crosslinking Copolymerization. Macromol. Rapid Commun. 2008, 29, 1965-1972.

(46) Yu, Q.; Xu, S.; Zhang, H.; Ding, Y.; Zhu, S. Comparison of reaction kinetics and gelation behaviors in atom transfer, reversible addition-fragmentation chain transfer and conventional free radical copolymerization of oligo(ethylene glycol) methyl ether methacrylate and oligo(ethylene glycol) dimethacrylate. Polymer 2009, 50, 34883494.

(47) Li, Y.; Ryan, A. J.; Armes, S. P. Synthesis of well-defined branched copolymers by quaternization of near-monodisperse homopolymers. Macromolecules 2008, 41, 5577-5581.

(48) Skelland, A. H. P.; Meng, X. The critical concentration at which interaction between polymer molecules begins in dilute solutions. Polym.-Plast. Technol. Eng. 1996, 35, 935-945.

(49) Gao, H.; Matyjaszewski, K. Synthesis of Star Polymers by A New "Core-First" Method: Sequential Polymerization of CrossLinker and Monomer. Macromolecules 2008, 41, 1118-1125.

(50) Zhu, S. Analytical functions for molecular weight and branching distributions in star-, comb-, and random-branched polymers. Macromolecules 1998, 31, 7519-7527.

(51) Barner-Kowollik, C.; Davis, T. P.; Stenzel, M. H. Synthesis of star polymers using RAFT polymerization: what is possible? Australian J. Chem. 2006, 59, 719-727.

(52) Boschmann, D.; Vana, P. Z-RAFT star polymerizations of acrylates: Star coupling via intermolecular chain transfer to polymer. Macromolecules 2007, 40, 2683-2693.

(53) Wang, W.-J.; Wang, D.; Li, B.-G.; Zhu, S. Synthesis and Characterization of Hyperbranched Polyacrylamide Using Semibatch 
Reversible Addition-Fragmentation Chain Transfer (RAFT) Polymerization. Macromolecules 2010, 43, 4062-4069.

(54) Fröhlich, M. G.; Vana, P.; Zifferer, G. Shielding Effects in Polymer-Polymer Reactions, 1. Macromol. Theory Simul. 2007, 16, 610-618.

(55) Teodorescu, M.; Matyjaszewski, K. Controlled polymerization of (meth)acrylamides by atom transfer radical polymerization. Macromol. Rapid Commun. 2000, 21, 190-194. 